\title{
The personal created through dialogue: enhancing possibilities through the use of new media
}

\author{
Sue Clegg*, Alison Hudson and Andy Mitchell \\ Sheffield Hallam University, UK
}

This paper explores the relationships between a number of different developments in higher education pedagogy, which are subsumed under the broad heading of progress files. The overall concern of the paper is to explore the ways in which personal reflection and learning is enhanced through dialogue. The paper explores the ways learners engage in dialogue in two environments that use different aspects of digital technologies to support the development of portfolios. The findings from the case studies point to the ways in which different technologies facilitated personal reflection mediated through sharing and dialogue. We develop the idea of affordances as a relationship whereby the learner is involved in a purposeful engagement with the possibilities created by their environment. The affordance of digitised technologies in supporting dialogue is, therefore, conceptualised in relation to the characteristics of the learner, not as a simple technology relation.

\section{Introduction}

The development of portfolios and the use of personal reflection to promote learning in higher education contexts are of course not new. The focus on development of independent learners is an international phenomenon. Nearly all national governments have been attempting to align their higher educational policies to the development of human capital in ways that could yield competitive advantage in the context of globalised markets (Clegg et al., 2003). Edwards and Usher (2000), for example, argue that there is a shift in emphasis in educational policy and practice from what they describe as the 'enlightened student' to 'autonomous/self-directed/flexible lifelong learners' (Edwards \& Usher, 2000, p. 55). This shift marks a transition away from an emphasis on the acquisition of discipline and subject knowledge, towards an emphasis on the individual learner. These shifts have received a major policy boost in

\footnotetext{
*Corresponding author. Learning and Teaching Institute, City Campus, Sheffield Hallam University, Sheffield, S1 1WB, UK. Email: S.Clegg@shu.ac.uk
} 
England with the new requirement on Higher Education Institutions to implement Progress Files in 2005/06 (Quality Assurance Agency, 2001). It is timely, therefore, to look at developments using portfolios and to consider some current practice that is attempting to use digitised technology to support individual reflection through the sharing of ideas. Our concern in this paper is not with the customisation of systems to facilitate the recording aspects of portfolio development, which are receiving much attention elsewhere (Joint Information Systems Committee, 2002), but rather with insights from smaller scale initiatives into the ways individualised learning can retain an essentially dialogical character (Koschmann, 1999).

There is considerable confusion and blurring of a number of practices in relationship to portfolio development. While the national policy steer may create the impression of a single focus, a cluster of terminology is currently being used to describe a variety of overlapping practices. This includes Progress Files, Personal Portfolios, Personal Development Planning, Professional Development Planning, Digitised Portfolios. This terminological confusion muddies claims about what is or can be effective (Gough et al., 2003; Clegg, 2004; Clegg \& Bradley, forthcoming). However, in this paper we want explore some rather more general theoretical questions about the nature of learning and the sorts of affordances between students and the learning environments involving new media.

Our argument operates at two levels, one theoretical and the other involving the exploration of specific contexts. This is necessary because, while at a surface level it may seem obvious that the sort of activity being encouraged is inherently individualistic and 'personal', we believe there are good theoretical reasons for believing that learning is inherently dialogic (Ashworth, 2004). There are sound pedagogical reasons, therefore, for designing this element into the production of personal portfolios. We argue that the emphasis on personal development is complementary to, and indeed enhanced by, learning in a collective context, where dialogue and interaction can inform the creation of personal narratives. We have chosen to analyse data from two very different examples of how this occurs in practice. The advantage of looking at dissimilar cases is that it removes the idea of affordance from its location as a way of thinking about technology to a way of thinking about affordance 'defined and measured relationally, with respect to an intentional act' (Stoffregen, 2000, p. 7). Our claim that it is possible to create the 'personal' in dialogue, and that this process may be enhanced using the potential of new media, involves analysing the intentions of both designers and learners as well as the different technologies. Our comparative approach also allows us to show how the meaning of 'portfolio' is located within distinct disciplinary traditions.

We have structured the paper around the theoretical elaboration of our core concerns with the personal in dialogue, and some observations about the way the concept of affordances might help us understand the environment/person relationship; these form the first part of the paper. The second part of the paper presents data from two case studies. The two settings we will describe relate to the use of digital portfolios by students studying design and technology in Initial Teacher Education, and students on an International Masters Programme in E-learning, Multi-Media 
and Consultancy. In both cases interaction and dialogue form a component part of the production of the personal statement, and in both cases the philosophy of reflection is embedded within the specifics of the discipline.

\section{The personal in dialogue}

There are a number of traditions within which we can understand the fundamentally interpersonal nature of human interaction and learning. The work of Lave and Wenger (1991) has been enormously influential in thinking about the interpersonal nature of learning, and it is this fundamental insight that underpins their ideas of legitimate peripheral participation:

Briefly, a theory of social practice emphasises the relational interdependency of agent and world, activity, meaning, cognition, learning and knowing. It emphasises the inherently socially negotiated character of meaning and the interested, concerned character of the thought and actions of persons-in-activity. (Lave \& Wenger, 1991, p. 50-51)

More recently, Ashworth (2004) has argued the priority of a participatory hermeneutics in which dialogue and communication are paradigmatic. His intention is to highlight the unique features of face-to-face interaction but the argument can be adduced for the special place of interactive over non-interactive forms of communication. Drawing on the work of Gadamer (1989), Ashworth explores the role of foreknowledge, the interpretations and understanding that the student brings with them, in learning. Entering into dialogue with others and attunement to their perspectives is crucial in learning. The student is confronted with new ideas and experiences, which are then reinterpreted in the light of their own starting points. In this sense, knowledge is always new for the student as it is part of the process of adjusting their own foreknowledge in new circumstances. Ashworth (2004) also reminds us of the importance of sharing in the emotional and motivational aspects of learning.

The concept of dialogue is, therefore, fundamental, and Koschmann (1999) has drawn on the work of Bakhtin to argue that it offers us a powerful way of thinking about Computer Support for Collaborative Learning. McKenna (2004) has highlighted the significance of the Bakhtinian construct of the reader-writer and argues that the idea of addressivity is crucial to understanding how people write using electronic media where the potential audience may be simultaneously both intimate and very wide. In line with these insights our argument is that dialogue should not be seen in contra-distinction to 'personal' knowledge and narratives. New knowledge of the personal, which comes about through reflection on the process of learning, does not occur in isolation but through the engagement with new frames of reference. The essentially dialogical nature of reflection includes tutor support for reflection (Bullock \& Jamieson, 1998), but it can also involve action learning groups and other mechanisms designed to maximise support (Chivers, 2003). Indeed, one of the paradoxes of greater individualisation and the need to create personal narratives is that these increase inter-dependence rather than diminish it (Beck \& Beck-Gernsheim, 2002). The sorts of selves that can be created in contexts where individuals are being 
exhorted to make them more employable, through creating distinctions between themselves (their curriculum vitae) and others, depends on a high degree of attunement to others' needs and perceptions (Beck \& Beck-Gernsheim, 2002). Our argument is, therefore, that in conditions where personal reflection is paramount, dialogue becomes even more, not less, important.

\section{Affordance}

The idea of affordance was developed in the context of visual perception (Gibson, 1979) and has been highly influential in thinking about the ways in which meaning is attributed to different technologies, based on the perception of what that technology makes possible/dis-allows (Conole \& Dyke, 2004). In particular, the concept has become a vehicle for thinking through the ways in which Information and Communication Technologies (ICT) is a medium that can enhance learning (Barnes, 2000). In the specific instance of this paper, our question is whether there are affordances that students and tutors perceive that encourage activities which support dialogue in project-based learning. The question is not simply a technological one. The fact that technologies (e.g. message boards, e-mail, etc.) permit dialogue does not mean that people perceive them in this way. E-mail, for example, was designed, and often used, simply to facilitate organisational information flows, but may unintentionally or intentionally facilitate dialogue. Other apparently inherently non-dialogical packages (e.g. PowerPoint) may, in particular learning contexts, become a way of encouraging sharing and conversations, as is illustrated by one of our case studies.

Our understanding of affordance has been influenced by Stoffregen (2000), who makes a distinction between affordances and the perception of events. Whereas events are properties of the external world, the concept of affordance focuses attention on the relational aspects of the (human) animal and its environments, and specifically on the properties of the animal in perceiving the possibilities afforded by that environment. This distinction is helpful as it shifts the focus away from the question of what the environment is, the world of events, to the perception of the possibilities of that environment. Stoffregen (2000) argues that perception of affordances may be more accurate than the perception of environmental properties, in our case all the things a particular ICT package can do. This chimes well with observations that users utilise only a fraction of the functionality of many systems, instead perceiving only those parts that act as affordances rather than the full range of functionalities that go unnoticed. We recognise that there are perils associated with 'borrowing' concepts from other cognate domains, which are not one's own. The justification must therefore be that they are useful in opening up questions and focusing attention on interesting aspects of learning environments. In this instance we believe there is good theoretical warrant from within different theoretical traditions for focusing on the relational and dialogue.

In our case studies we are interested in the affordances for dialogue in creating personal portfolios. The affordances of virtual environments are different from those 
of the face to face, where gesture, expression, and the warmth that may be generated by reciprocity are features. Of course these features can have negative as well as positive impacts: mis-reading of body language as indifference, or comments that act as affronts to a learner's dignity can dis-able learning. Our questions are about the ways in which different sorts of sharing (e.g. of artefacts and ongoing written reflections) can constitute dialogue. We have chosen to conceptualise the personal in dialogue as the starting point for assessing affordances, rather than simply the personal as such, as our professional understanding (Lave, 1988, 1996; Lave \& Wenger, 1991) in designing these learning environments led us to believe that sharing is a powerful prompt to the elaboration of personal knowledge.

\section{Case study 1: International Masters Programme in e-Learning Multimedia and Consultancy}

\section{Pedagogical approach}

The context for this case study is the International Masters Programme in e-Learning Multimedia and Consultancy (Sheffield Hallam University, UK). The Programme was developed from the Advanced Curriculum Development Project supported by the European Commission under the SOCRATES programme (1998-2001) and has involved an active partnership between Arnhem-Nijmegen University of Professional Education in the Netherlands and Sheffield Hallam University in the United Kingdom. The programme is embedded in professional practice and seeks to develop the profile of the 'problem solver'/team coordinator at the interface of pedagogical, technological and cultural dimensions of development.

The framework for the programme is founded on a socio-constructivist perspective of teaching and learning that places emphasis on communication, interaction and collaboration. The programme as a whole is framed within a Virtual Learning Environment. It has an international student cohort and a tutor team from partner universities. It is designed to integrate online learning, local studies and independent learning, and it emphasises the importance of peer and formative assessment practices.

In designing and planning the programme considerable emphasis has been placed on enabling collaborative activity in multinational teams. In relation to this aspect we share the general perspective offered and the distinction between cooperation and collaboration made by Lehtinen et al. (1999). They highlight the way in which research on the role of collaboration in learning has searched for more meaningful theoretical frameworks that could better guide the development of technology-aided learning environments. They also highlight the distinction between cooperation and collaboration based on different ideas of the role and participation of individual members in the activity. A project-based and team-based approach towards learning underpins each module of the programme, which involves a gradual shifting balance from more directed and supported learning to more independent learning, through the lifespan of each module. 


\section{The module}

The specific context for this case study is the second module of the programme, the Digital Media Applications (DMA) module. This module aims to enable students to develop an overview and a critical appreciation of the development process and the potential and limitations of DMA.

The module involves working online in international project teams to produce a DMA prototype. The activity is used as the basis for personal reflection, the outcomes from which are compiled into a digital portfolio (Figure 1). The portfolio reflects the following aspects:

- A team report including the DMA prototype, the project aims and objectives, the project design and development plan, technical specifications and copyright issues, and the evaluation of the prototype and recommendations for further development.

- A personal evaluation of the development process with evidence of individual contributions to the team effort.

- A personal critical reflection on the learning process with reference to DMA and ICT developments.

The digital portfolio is the main means of summative assessment in the DMA module. An aspect of the portfolio and of the learning process is an ongoing reflective diary that students post in the open learning environment. The diary is seen as one technique for accumulating data as part of an action learning approach

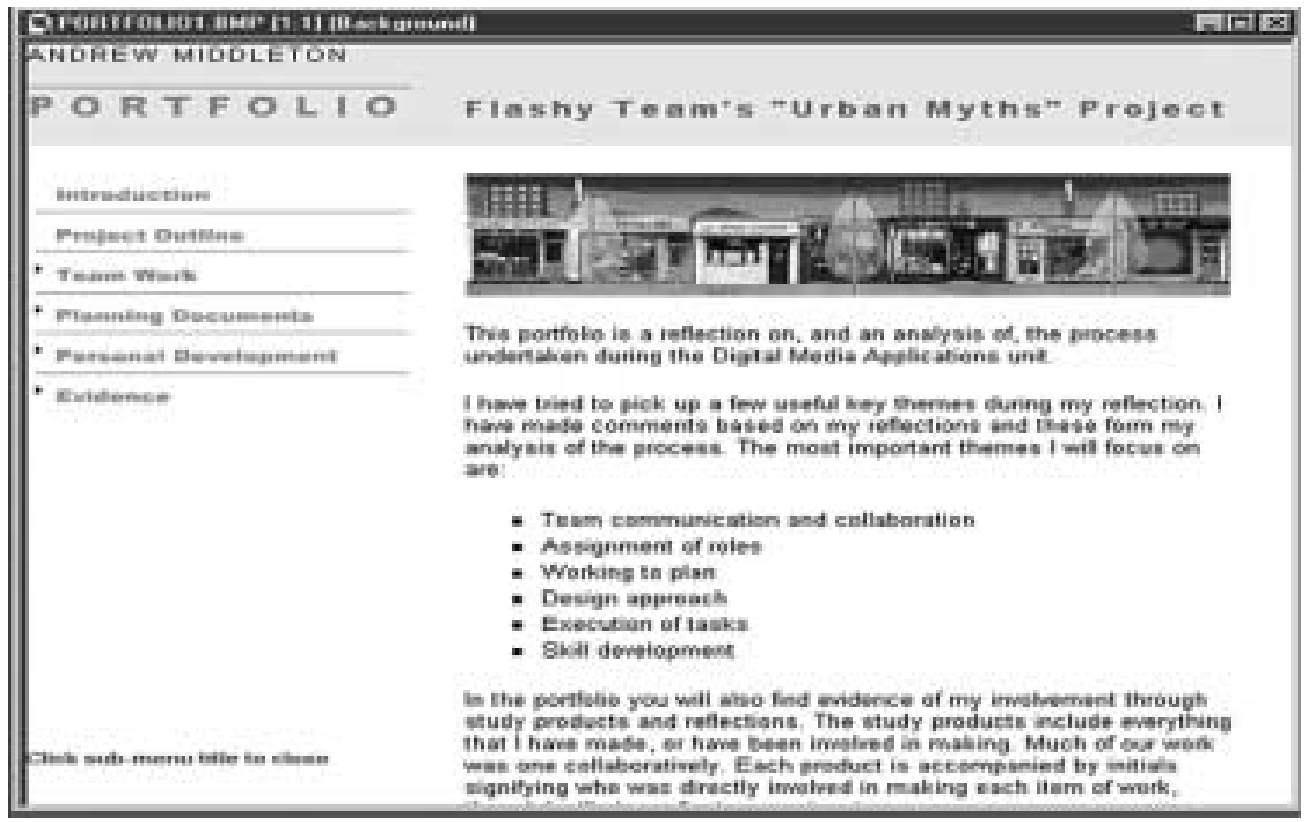

Figure 1. An example of a digital portfolio (permission to use this example granted by the student) 
(Kember, 2000) and is intended as an aid for promoting systematic reflection on learning and as a tool for linking theory with practice. Within the context of their portfolio the students are asked to provide an account based on their personal reflection of the process of developing the DMA prototype and of their learning. The reflective diary is used as a means to support this process. By reflecting systematically on experience at an individual level, the aim is to help link theory with practice at the wider social and communal level.

\section{Research study 1}

\section{Method}

The starting point for the research was the standard approach towards module evaluation through means such as end-of-unit questionnaires to both staff and students. In addition, we have adopted an ethnographic approach with the aim of exploring emergent issues as they arise naturally through the process of enquiry. In relation to this aspect we have found the approach of responsive evaluation outlined by Stake (1976) to be particularly relevant. This approach aims to be responsive to the concerns and issues of the 'stakeholders' involved in evaluation.

As part of the DMA module students keep an ongoing diary in the open learning environment. The diary is seen as one technique for accumulating data as part of an action learning approach. An agreed statement of research ethics was negotiated at the outset of the project to allow the diaries to be used as a source of data collection with the aim of following up emergent themes in seeking to achieve a responsive mode of enquiry. In total, 10 diaries were analysed by an independent researcher working closely with the course team at an early stage in the development of the programme (Hudson et al., 2002). In addition, at the end of the module, students complete an online questionnaire and contribute to an end-of-module discussion with their tutors at the local centres. The questionnaire was a means of collecting data on the student experience and of investigating the importance and meaning of being part of a learning community. This ongoing action research process has taken place over a four-year period and has involved up to 80 students.

\section{Findings}

Five inter-related and overlapping themes emerged from the analysis of the diaries. These were: listing of process, culture, language, communication and collaboration. Other significant threads that emerged were around the areas of action and activities, obligation and identity (Hudson et al., 2002).

The diary entries represented snapshots of the students' learning experiences, which are in turn utilised as study aids. The reflective component of the diary was designed to encourage students to think and re-examine their actions and activities, their obligations, and their sense of identity as students working together within an international and virtual context. 
The way in which the diaries were used at different times reflects the range of learning opportunities that are provided in the use of such a strategy. A diary is generally perceived as a personal and private thing, yet in this context it was available for everyone to see and comment on, which provided an interesting insight into how the diary was perceived at different times and the specific functions it performed. The value of being able to share issues openly was instrumental in encouraging other team members and tutors to engage in wide-ranging discussion.

The ongoing evaluation has highlighted the importance of dialogue within the context of collaboration. This was emphasised by one student who argued that collaboration in any environment is about needing each other.

To open a discussion, to publish work or ask a question, in short to let people know where you are in knowledge, thinking and questions is the only way to learn and get the support you need. The feedback and comments are essential to learning.

\section{Case study 2: e-portfolios for Design and Technology}

\section{Pedagogical approach}

This case study examined the work of 41 Initial Teacher Education students studying Design and Technology with Qualified Teacher Status at Sheffield Hallam University. Students complete a module developing their ability to design and manufacture products using a range of skills, processes and materials. This also involves the presentation of a portfolio of evidence to support a number of physical product outcomes they design and manufacture. The compilation process is valued for a number of reasons, including:

- Organising resources arising from the students' research to inform decisionmaking.

- Assisting the designer to reflect on decisions made and their own learning.

- Providing a focus to inform discussion with others and providing an archive for academic accreditation.

However, the effectiveness of this process in terms of efficiency, effectiveness and ability to develop reflective capability has been questioned. Whereas annotation within the portfolio is encouraged, submissions do not lend themselves readily to the active recording of reflection. Hence the articulation of thought processes critical for both reinforcing learning and providing valuable insight for the tutor is missing. Reflection tends to be restricted to short annotations relating to the product design and ideas being developed but not to the learning taking place.

Developing students' understanding as to the true value of compiling a portfolio is advantageous and provides a mechanism for prompting reflection.

Design learning should strive towards the situation where new designers constantly reflect upon and critically examine their design practice. They should regard the design practice itself as a result of a design process and therefore possible to change and redesign. (Stolterman, 1994, p. 458) 
Although use is made of digital technology to generate the content of a portfolio, the common perception remains that, in order to make it accessible to others, it must first be transferred to paper. This traditional approach may be restricting the benefit that can be drawn from the compilation and subsequent use of portfolio documenting activity. The use of IT enables students to undertake and engage in increasingly sophisticated design activity, but also has potential to assist organisation and reflection. Only limited exploration of the potential for this has been carried out in the area of design and technology education.

\section{The module}

The concept of an 'e-portfolio' was introduced to the cohort, and the requirement was made that they compiled this ready for submission at the end of the module. An e-portfolio is a means of combining textual and visual material together digitally, in a form that can be transmitted and read electronically. Students were required to use Microsoft PowerPoint to create their e-portfolios and upload them to a specially created 'Blackboard' e-learning 'site' accessible only to the group through the university website. The site also contained exemplar material and resources to inform their own design process. Although specialist portfolio packages are available, PowerPoint was selected due to its ease of use. It is also commonly available so students were able to transfer their work between machines both inside and outside the university as necessary. The advantages and simplicity of PowerPoint were illustrated, and emphasis was placed on the need to keep presentations simple and not use an excessive array of effects provided within the software. Individual e-portfolios were limited to five annotated slides providing reflection and comment using the Notes facility available in the software. This important aspect enabled recording of reflection that was to remain private between tutor and student. Portfolios were posted on Blackboard and made available as a PowerPoint show, thus enabling students to view each other's work and share in the design process but not allowing student access to the reflection and comments contained in the Notes facility.

\section{Research study 2}

\section{Method}

The researchers were concerned with the students' experience, the nature of the learning and the outcomes produced rather than the evaluation of specific software. A qualitative approach was taken to enquire into the attitudes of the participants in the pilot project. The researchers were interested in examining how production of the e-portfolio contributed to the learning process of students completing this module and their views about the use of PowerPoint as a means of sharing the design process. Data were collected from multiple sources-questionnaires, semi-structured interviews and the portfolio reflections-allowing triangulation. A total of 25 questionnaires were returned from the cohort of 41, and 24 interviews were conducted 
individually and in small groups. The researcher also independently analysed a sample of the portfolios. All the data collection and analysis was undertaken by an independent researcher working alongside the course team (Mitchell et al., 2003).

\section{Findings}

The value of reflection and its recording as a tool to enhance learning both as work progresses and summatively is seen as important. One student reported:

I think the realisation that others were going to see your work made me more reflective and critical of my work to date.

Some felt that working electronically had a positive effect and actively assisted their ability to reflect on their practice. Inexperience in the use of PowerPoint seemed to have little effect on students' perceived ability to be reflective. Sixty-eight per cent felt confident in their ability to be reflective and record, regardless of their experience. However, the nature of much of the reflective comment tended toward description. The results indicated that additional teaching in the use of reflective techniques would benefit the majority of students. Attention needs drawing to the benefits of generating a critical dialogue, recording the iterative process between thinking and doing associated with designing and making.

A number of conclusions can be drawn from the experience that will be used to inform future developments in the use of e-portfolios in this course. Those students with limited IT experience would benefit from additional training in the use of PowerPoint and digital imaging. Acquisition of these skills would be enhanced by making exemplar e-portfolios available electronically, including reflective notes.

No framework was provided except the stipulation over the number of slides and the need to display a representative range of communication techniques developed during the module. Some students reported that they would feel more secure if a more structured format had been provided. A lack of clarity about what was expected led to some confusion over the extent to which the portfolio was being assessed for presentation as opposed to reflection. It is likely, however, that over-prescription may impact on the opportunity for creativity in the compilation of the e-portfolio.

Some students displayed a general lack of clarity about the use of reflection, and in particular its use in the distillation of thinking and its effect on refining decision making. As a consequence there was a tendency to leave the compilation of the electronic portfolio to the end. This can be partly explained by the lack of experience and initial confidence in compiling their first e-portfolio, suggesting the need for further guidance as to the purpose and value of the e-portfolio, and more encouragement to spread its compilation to run concurrently with the process of designing and making. This is consistent with Tomlinson's suggestion that:

... reflective thinking should not just occur before or after the action but if possible also in the midst of it. (1999a, p. 408)

The quality of submitted work was considered by tutors to represent an improvement on previous cohorts' paper-based versions. Students expressed the view that, as their 
work was going to be put on show and viewed by others (peers), they were highly selective as to what they included. For many students, digitising their work provided them with the opportunity to improve the presentation quality.

Students benefited from being able to view their peers' submissions via Blackboard at the end of the module. This enabled them to see their work in a group context and gain substantially from observing evidence of others' design activity, including different approaches and subsequent outcomes. One student summarised this as:

My learning experience has been enhanced by sharing information with my peers. This is an ideal way to see other people's work and get an idea of how they feel about the course.

\section{Conclusions}

We suggested in our introduction that the concept of affordance is useful in highlighting the relational aspects of the perception and of the capacity of perceiving the possibilities afforded by an environment. In both our examples it was the pedagogical vision of course designers, based on both theoretical understanding and practice, and grounded in disciplinary know-how, that structured those aspects of the media employed. This orientation shifts the concern with media per se to the particularities of pedagogical purpose. The actual media used were suited to the context: in one case, an off-the-shelf common package that required relatively low levels of computing skill in the preparation of the portfolio, but with the capacity for enabling the visual aspects of the design process to be shared; in the other case, a more sophisticated Web-designed environment that allowed for greater connectivity between elements. This diversity and plurality is a feature not only of the case studies reported here, but of the many of the close-to-practice reports in the literature of academics experimenting with new media. This can create frustration, as it means that, at the level of description, each case appears unique and, therefore, the learning from these experiments is not easily generalised. However, by asserting the primacy of pedagogic purpose in the perception of affordances offered by the media, the debate can be shifted to where it properly belongs, namely the underlying principles-in our case, the importance of the dialogic in reflective activity.

Both our examples suggest that dialogue and the ability of students to share in the processes that contribute to the production of a portfolio appear to be key. The particular affordances of new media in enabling this form of exchange in ways that in paper-based systems are more cumbersome, or even impossible, is therefore a crucial design element. We believe that by designing in dialogue, personal reflection can be enhanced by making visible (both literally and metaphorically) the processes involved in creating a portfolio. This is not without difficulties. The Design and Technology students, in particular, found the articulation of process hard. This should not surprise us as the reflective practice literature (Tomlinson, 1999a, 1999b; Clegg et al., 2002) has drawn attention to the importance of the tacit and non-cognitive aspects of practice. However, we believe there is good theoretical and practical pedagogical warrant for conceptualising the individualisation involved in reflective self as involving greater levels of interpersonal awareness and attunement. 
The choice of whether to use e-portfolios should be shaped by these underlying considerations, rather than the functionality of any particular Virtual Learning Environment. The perception of affordances of any particular media rests with the skills of the course designer in recognising his/her pedagogical purposes. The challenge for us as practitioners and researchers is to try to make these processes explicit and to model them in the creation of learning environments that make active dialogue a possibility.

\section{Acknowledgements}

The authors would like to thank John Steel and Sally Bradley, respectively, who were the independent researchers involved in the original data collection and analysis. Fuller co-authored accounts of the case studies are referred to in the text and appear in the reference list.

\section{References}

Ashworth, P. (2004) Understanding as the transformation of what is already known, Teaching in Higher Education, 9(2), 147-158.

Barnes, S. (2000) What does electronic conferencing afford distance education?, Distance Education, 21(2), 236-247.

Beck, U. \& Beck-Gernsheim, E. (2002) Individualization (London, Sage).

Bullock, K. \& Jamieson, I. (1998) The effectiveness of personal development planning, The Curriculum fournal, 9(1), 63-77.

Chivers, G. (2003) Utilising reflective practice interviews in professional development, fournal of European Industrial Training, 27(1), 5-15.

Clegg, S. (2004) Critical readings: Progress files and the production of the autonomous learner, Teaching in Higher Education, 9(3), 287-298.

Clegg, S. \& Bradley, S. (forthcoming) Models of models of personal development planning: practice and processes, British Educational Research fournal.

Clegg, S., Tan J. \& Saeidi, S. (2002) Reflecting or acting? Reflective practice and continuing professional development in the UK higher education, Reflective Practice, 3(1), 131-146.

Clegg, S., Hudson, A. \& Steel, J. (2003) The emperor's new clothes: globalisation and e-learning, British Fournal of Sociology of Education, 24(1), 40-53.

Conole, G. \& Dyke, M. (2004) What are the affordances of information and communication technologies, ALT-f, 12(2), 113-124.

Edwards, E. \& Usher, R. (2000) Globalisation and pedagogy: space, place and identity (London, Routledge).

Gadamer, H. G. (1989) Truth and method (London, Sheed and Ward).

Gibson, J. J. (1979) The ecological approach to visual perception (Boston, Houghton-Miffin).

Gough, D. A., Kiwan, D., Sutcliffe, S., Simpson, D. \& Houghton, N. (2003) A systematic map and synthesis review of the effectiveness of personal development planning for improving student learning (London, EPPI-Centre, Social Sciences Research Unit).

Hudson, B. (2002) Holding complexity and searching for meaning-teaching as reflective practice, fournal of Curriculum Studies, 34(1), 43-57.

Hudson, B., Hudson, A. \& Steel, J. (2002) Orchestrating interdependence in a multinational virtual learning community, paper presented at ECER 2002-European Conference on Educational Research, University of Lisbon, 11-14 September (Leeds, Education-line, Brotherton Library, University of Leeds). 
Joint Information Systems Committee (2002) Developing Learner Profiles Across FE and HE. Available online at: http://www.jisc.ac.uk/index.cfm?name=project_cra\&src=alpha (accessed ?).

Kember, D. (2000) Action learning and action research: improving the quality of teaching and learning (London, Kogan Page).

Koschmann, T. (1999) Towards a dialogic theory of learning: Bakhtin's contribution to understanding learning in settings of collaboration, in: C. Hoadley \& J. Roschelle (Eds) Proceedings of the Computer Support for Collaborative Learning (Mahwah, NJ, Lawrence Erlbaum).

Lave, J. (1988) Cognition in practice (Cambridge, Cambridge University Press).

Lave, J. (1996) Teaching, as learning, in practice, Mind, Culture and Activity, 3(3), 149-164.

Lave, J. \& Wenger, E. (1991) Situated learning: legitimate peripheral participation (Cambridge, Cambridge University Press).

Lehtinen, E., Hakkarainen, K., Lipponen, L., Rahikaianen, M. \& Muukkonen, M. (1999) Computer supported collaborative learning: a review. Available online at: http://www.kas.utu.fi/ clnet/clnetreport.html (accessed 13 December 1999).

McKenna, C. (2004) Words bridges and dialogue: issues of audience and addressivity in online communication, in: S. Bayne \& R. Land (Eds) Issues in cyberspace education (London, Routledge).

Mitchell, A., Grover, P. \& Bradley, S. (2003) Electronic portfolios for design and technology, paper presented at the Design and Technology Association Conference, Warwick Hilton, 2-5 July.

Quality Assurance Agency (2001) Guidelines for progress files. Available online at: http:// www.qaa.ac.uk/crntwork/progfileHE/guidelines/progfile2001.pdf (accessed 14 January 2005).

Sheffield Hallam University (no date) International Masters Programme in E-Learning Multimedia and Consultancy. Available online at: http://www.shu.ac.uk/msce-learning/ (accessed 14 January 2005).

Stoffregen, T. A. (2000) Affordances and events, Ecological Psychology, 21(1), 1-28.

Stoke, R. E. (Ed.) (1976) Case studies in the evaluation of educational programmes (OECD Centre for Educational Research and Innovation).

Stolterman, E. (1994) Guidelines or aesthetics: design learning strategies, Design Studies, 15(4), $448-458$

Tomlinson, P. (1999a) Conscious reflection and implicit learning in teacher preparation, Part 1: recent light on an old issue, Oxford Review of Education, 25(3), 405-424.

Tomlinson, P. (1999b) Conscious reflection and implicit learning in teacher preparation, Part 2: implications for a balanced approach, Oxford Review of Education, 25(4), 533-544. 